\title{
THE SCRIBE'S COLUMN
}

\section{Whatever Else It Is It Isn't Gricket}

Following a visit by the Hospital Cricket Advisory Service we have reorganized our 'isolated Victorian psychiatric hospital cricket team' on multidisciplinary lines. In the hope that this experiment may be of interest to others similarly situated we submit this report.

Formerly the cricket team had a Captain who was largely responsible for batting and bowling orders and strategy and tactics on the field. He was supported by a Vice-Captain and in general by the rest of the team. An administrative secretary arranged fixtures as well as, through the kitchen staff, team teas. The hospital gardeners prepared the wicket and, with the Captain, arranged for the rolling and watering of the wicket. (One advantage of this old-fashioned arrangement was that it was often possible to water one end more than the other.)

All this has now been changed. In the first place, as the Cricket Advisory Service pointed out, these arrangements were not multidisciplinary and lacked consensus decisions and participative management. It was held to be unfortunate that the Captain should be thought of as the hierarchical head, more particularly inasmuch as he was quite good at cricket.

The various members of the team have now arranged to meet regularly with the administration, the gardeners, the kitchen staff and engineers (water suppliers) and of course the Umpires. A Principal Clinical Psychologist who, while lacking much knowledge of cricket, rather fancies herself as an organizer, has come along for good measure. Unfortunately she attends so many committees already that we have not seen much of her.

It really has gone rather well. We are still wondering whether we should include our opponents so that we could get them to work with us in the hope that they would see what we were trying to do (i.e. get them out). We were greatly excited by the idea of a protocol or mutually agreed contract, as suggested by the National Association for Cricket Health. Such a contract would make it clear that if our opponents did not play along with us they would have to get out. We have also been looking at the possibility of incorporating the spectators. It was suggested that the rational course would be to form a Community Cricket Council (under the Chairmanship of some well-meaning local figure) so that they might not only make comments from the sidelines but at times be encouraged to invade the field of play.

We have had some failures. The Umpires proved resistant to the idea of change, could not understand the new rules and certainly did not see themselves as
Ombudsmen. There have been unfortunate diffculties with the kitchen staff. The tea ladies have felt (and have consulted their Union about this) that tea should be served to suit their convenience and not that of the players. They have, therefore, threatened to withdraw their labour unless their wishes rather than those of the players are considered paramount. Another difficulty has been the attitude of some of our batsmen who have felt threatened by hostile bowling. They have argued that in such a case they should not bat unless they get either additional money or additional protection or both, and have further argued that only batsmen of proven competence in a secure situation should be asked to undertake this task. Interim secure protective apparatus is about to be supplied, but the problem is not particularly acute because the current 'resource constraints' have meant that we haven't actually got any balls. (RAWP, please note).*

We have not yet been able to evaluate our newfound consensus approach. It has proved difficult to call a team meeting to decide whether or not to take a quick single or to have two slips and a gully or something else, let alone to know when to declare, and so on.

It is true that so far not a ball has been bowled, but we are hopeful that we shall soon overcome the minor technicalities of getting a cricket match under way. We have got a splendid fellowship, and we are all on Christian or forename terms where applicable, following the example of the Hospital Cricket Advisory Service itself on their first visit ('I'm Bruce the batsman and this is Lucille our long stop', etc).

Occasional interpersonal difficulties (i.e. spiteful gossip) have sometimes threatened to disrupt the team activities, and unfortunately even our group therapy meetings have not altogether overcome this. At one time matters got so out of hand that the possibility of a Committee of Inquiry under the appropriate Rules of Cricket was mooted. In the event it has been decided to seek the advice of a Working Party limited to not more than 50 people. We are hopeful that given a few words of encouraging advice by the President of the National Mental Health Cricket Glub we shall soon do splendidly and, without in any sense going back to the old methods of playing cricket, be able to make striking advances. Who's for tennis?

Ezra the Scribe

* For the benefit of the (possibly few) readers who may have had no dealings with this body: the initials stand for Resources Allocation Working Party-EDs. 